\title{
Role of Psychosomatic Capital on Employee Attitudes, Behavior and Performance
}

\author{
Mr. P. Ramesh ${ }^{1}$, Mr.T.Narayana Rao ${ }^{2}$
}

\begin{abstract}
The focus of all aspects human resource development is on developing the most superior workforce so that the organization. The performance-based goals is to be sensitive to the addition of a performance contingency to the achievement context, because these types of goals are inherently focused on external evaluation and are presumed to be responsive to the internal constraints. There is no gain-saying the fact that individual's skills and techniques are significant determinants of such person's work performance. These could be acquired through psychological resources along with training and development.

The positive core construct of PsyCap (psychological capital), consisting of the psychological resources of hope, efficacy, resilience, and optimism, has recently been demonstrated to be open to human resource development (HRD) and performance management.

The PsyCap has now grown to the point that a quantitative summary analysis of its impact on employee attitudes, behaviors, and especially performance is needed. The results indicated the expected significant positive relationships between PsyCap and desirable employee attitudes like: job satisfaction, organizational commitment, psychological well-being, desirable employee behaviors (citizenship), and multiple measures of performance etc.,

Finally, the analysis hence this article summarizes of moderator revealed the relationship between PsyCap and employee outcomes we restrings in studies conducted in India and in the service sector. These results provide a strong evidence-based recommendation for the use of PsyCap in HRD and performance programs. Theoretical contributions, future research directions, and practical guidelines for HRD conclude the article.
\end{abstract}

\section{Theoretical Foundation}

In the field of psychology, there has been concern and debate throughout the years on the relative emphasis and conceptualization of the situation ally based, state- 250 F. Luthans, B. J. Avolio, F. O. Walumbwa, and W. Li (C) Blackwell Publishing Ltd 2005. like psychological capacities versus the relatively fixed, trait-like personality constructs (e.g. Allen and Potkay, 1981). However, in organizational behavior, this concern and distinction has received relatively little attention, with a few exceptions (e.g. Chen, Whiteman, Gully, and Kilcullen, 2000) because of the dominance of dispositional personality and motivational constructs. To date, there have been only a couple of studies examining the role that individual positive psychological states such as hope (e.g. Peterson and Luthans, 2003) or optimism (e.g. Seligman, 1998a) can have on employees' performance, and there has been no research on the role that overall psychological capital can play in predicting the performance of workers. Drawing from positive psychology (Seligman, 1998b; Seligman and Csikszentmihalyi, 2000; Snyder and Lopez, 2002), the positive organizational behavior (POB) approach (Luthans, 2002a, 2002b, 2003) incorporates overlooked state-like positive psychological strengths and capacities such as hope, optimism, efficacy and resiliency. These positive states, which in aggregate are referred to as a core factor of psychological capital (Luthans, Luthans, and Luthans, 2004; Luthans and Youssef, 2004), may have important implications for employee work motivation (Stajkovic, 2003) and authentic leadership (Avolio, Gardner, Walumbwa, Luthans and May, 2004; Gardner, Avolio, Luthans, May, and Walumbwa, 2005; Luthans and Avolio, 2003). Luthans (2002b, p. 59) specifically defines POB as 'the study and application of positively-oriented human resource strengths and psychological capacities that can be measured, developed, and effectively managed for performance improvement in today's workplace'. Thus, to be considered as a POB state contributing to psychological Capital, the following criteria must be met: (1) positive, strength-based, and relatively unique to the organizational behavior field; (2) theory and research based; (3) valid measures; and most importantly, (4) state-like and thus open to development and performance management (see Luthans, 2002a, 2002b, 2003). These inclusion criteria separate the POB states from the positively-oriented popular literature (e.g., Steven Covey's Seven Habits or Spencer Johnson's Who Moved My Cheese) and the more macro-oriented positive organizational scholarship, (Cameron, Dutton, and Quinn, 2003). The POB states are also distinct from the dispositional, relatively fixed self-evaluation constructs ( Judge, Erez, Bono, and Thoresen, 2002; Judge and Bono, 2001), the 'Big Five' personality traits (Barrick and Mount, 1991; Mount, Barrick, and Stewart, 1998), self-esteem ( Judge and Bono, 2001), positive affectivity (Erez and Isen, 2002), and emotional intelligence (Goleman, 1995; Mayer, Salovey, and Caruso, 2000). Personality traits such as 
conscientiousness or self-esteem are strength-based and positive, and have a strong theory and research foundation with valid measures. However, they are also trait-like, i.e. relatively dispositional and fixed, and thus not easily open to development and change. Recently emerging strengths such as The Psychological Capital work on positive emotions and possibly courage (Peterson and Seligman, 2004; Putnam, 1997), and even humility (Tangney, 2000; Vera and Rodriguez-Lopez, 2004;) may meet POB criteria for future research in the workplace.

\section{The Background and Meaning of Psychological Capital}

Although modern psychology started with the charge to not only help people with problems but also identify and build strengths in people, through the years virtually all the attention has been devoted to mental illness - what is wrong with people and how to repair the damage. Several years ago, the president of the American Psychological Association (APA) and a well-known research psychologist, Martin Seligman, proactively started the positive psychology movement in his address to the APA (Seligman, 1998b). He charged the field of psychology to use scientific methods to study and discover the strengths that allow individuals, groups, organizations, and communities to thrive and prosper (Seligman and Csikszentmihalyi, 2000). At this time, the Gallup Organization, best known for its polls, but also with a fast-growing consulting practice based on strength-based management, partnered with Seligman and colleagues to sponsor the annual Positive Psychology Summits starting in 1999. As an outgrowth of these conferences, Luthans (2002a, 2002b) extended this seminal work in positive psychology to the work place and called it positive organizational behavior or POB. A parallel development by a group of researchers at the University of Michigan also began to draw from the positive psychology movement at the more macro, organizational level and called it positive organizational scholarship or POS (Cameron, Dutton, and Quinn, 2003). Initially, the theory-building for POB identified and supported confidence (or self efficacy), hope, optimism, subjective well-being (or happiness), resiliency, and emotional intelligence as meeting the POB criteria of being not only positive, but also unique to the organizational behavior field, based on theory and research with valid measures, and state-like openness to development, change, and management for performance improvement (Luthans, 2002a, 2002b, 2003). Subsequent POB theory building, research, and applications have focused mostly on hope, resiliency, confidence, and optimism and their relationship to leadership (Avolio, Gardner 252 F. Luthans, B. J. Avolio, F. O. Walumbwa, and W. Li @ Blackwell Publishing Ltd 2005. et al., 2004; Luthans and Avolio, 2003; Luthans, Luthans, Hodgetts, and Luthans, 2002; Luthans, Van Wyk, and Walumbwa, 2004; Peterson and Luthans, 2003). Considerable prior theory and research (e.g. Bryant and Cvengros, 2004; Luthans and Jensen, 2002; Magaletta and Oliver, 1999; Snyder, 2000; Snyder, Rand, and Sigmon, 2002) have clearly demonstrated each of these positive psychological constructs to be conceptually independent with discriminately valid measures. Recent work by Luthans and colleagues (e.g., Luthans, Luthans, and Luthans, 2004; Luthans and Youssef, 2004) have combined or bundled POB states conceptually into the higher-order core construct of what they call 'positive psychological capital' or PsyCap. They propose that psychological capital goes beyond the now widely recognized human capital (i.e. what you know, see O'Leary, Lindholm, Whitford, and Freeman, 2002) and social capital (i.e., who you know, see Adler and Kwon, 2002), and is basically 'who you are' (Luthans, Luthans, and Luthans, 2004; Luthans and Avolio, 2003). At the individual level, psychological capital is a psychological resource that may fuel growth and performance. At the organizational level, similar to human and social capital, psychological capital may provide leverage, return on investment, and competitive advantage through improved employee performance. Specifically, psychological capital is defined as a core psychological factor of positivity in general, and POB criteria meeting states in particular, that go beyond human and social capital to gain a competitive advantage through investment/development of 'who you are' (Luthans, Luthans, and Luthans, 2004; Luthans and Youssef, 2004). The key points of psychological capital are: (1) based on the positive psychology paradigm (i.e. the importance of positivity and human strengths); (2) includes psychological states based on positive organizational behavior or POB criteria (i.e., unique, theory/research, valid measurement, and state-like); (3) goes beyond human capital (i.e. what you know) and social capital (i.e. who you know) to 'who you are'; and (4) involves investment and development (i.e. such as economic/financial capital) for a return yielding performance improvement and resulting competitive advantage. Thus, to begin, this study explored not only the states of hope, optimism, efficacy and resiliency, but also combined them into the core construct of psychological capital, to empirically determine whether they are related to Institutional workers' performance. The following briefly summarizes the theory and research of the four POB criteria meeting states of hope, resiliency, efficacy and optimism that make up the psychological capital examined in this study.

\section{The Hope State}

In positive psychology, hope is generally defined as the perceived capability to derive pathways to desired goals and motivate oneself via agency thinking to use The Psychological Capital of VLNV Institutional 
Workers 117. However, as used in POB, hope is conceptualized as state-like and is derived from the work of a positive motivational state that is based on an interactively derived sense of successful. Although there is considerable research evidence that hope has a positive impact on academic performance These studies suggest that those who are hopeful are likely to be motivated and more confident in taking on a task, and are likely to have alternative pathways when obstacles are met, resulting in higher performance. Such hope would seem to be a valuable contribution to their psychological capital and have a positive impact on their performance.

\section{The Resiliency State}

In POB, resiliency is defined as the 'positive psychological capacity to 'bounce back' from adversity, uncertainty, conflict, failure, or even positive change, progress and increased responsibility. Work in clinical and positive psychology suggests that highly resilient individuals tend to be more effective in a variety of life experiences, including adjustment and development under a variety of life-course threatening conditions. In the workplace, resiliency has been given only surface attention There have been a few attempts to conceptually link resiliency to workplace performance. As part of psychological capital, it is been proposed that resiliency will be positively related to performance. This is because highly resilient individuals are likely to be creative, adaptive to change, and persistent in dealing with adversity, resulting in improved performance in the rapidly transforming workplace. Such rapid transformation is perhaps most characteristic in VLNV Institution, and therefore the resiliency of these institutional workers would be especially critical to their psychological capital and related to their performance.

\section{The Self-efficacy State}

Psychologist Albert Bandura has defined self-efficacy as our belief in our ability to succeed in specific situations. Your sense of self-efficacy can play a major role in how you approach goals, tasks, and challenges. The concept of self-efficacy lies at the center Bandura's social cognitive theory, which emphasizes the role of observational learning and social experience in the development of personality. According to Bandura's theory, people with high self-efficacy - that is, those who believe they can perform well - are more likely to view difficult tasks as something to be mastered rather than something to be avoided. Self-efficacy is "the belief in one's capabilities to organize and execute the courses of action required to manage prospective situations". In other words, self-efficacy is a person's belief in his or her ability to succeed in a particular situation. It was described these beliefs as determinants of how people think, behave, and feel. self-efficacy can have an impact on everything from psychological states to behavior to motivation. Virtually all people can identify goals they want to accomplish, things they would like to change, and things they would like to achieve. However, most people also realize that putting these plans into action is not quite so simple. It had been found that an individual's self-efficacy plays a major role in how goals, tasks, and challenges are approached. People with a strong sense of self-efficacy, View challenging problems as tasks to be mastered, Develop deeper interest in the activities in which they participate, Form a stronger sense of commitment to their interests and activities, recover quickly from setbacks and disappointments.

\section{The Optimism State}

Traditionally in psychology, optimism has been conceptualized as a goal-based construct that occurs when an outcome has substantial value. Tiger defined optimism as being 'a mood or attitude associated with an interpretation about the social or material - one which the evaluator regards as socially desirable to his/her advantage, or for his/her pleasure'. Unlike the other POB states, there is some research demonstrating that optimism is directly related to work performance. Consistent with this work, psychological capital proposes that people who have 'realistic' optimism are likely to remain committed, leading to higher performance. This is because individuals are likely to use various attributional explanatory styles as a way of adapting to the situation at hand. Thus, to the optimist, setbacks are not necessarily seen as failures, but as challenges and opportunities that can be improved on for success. Such realistic optimism would seem to be especially relevant to the workers' psychological capital and related to their performance.

\section{Human Resources Development}

HRD as a theory is a framework for the expansion of human capital within an organization through the development of both the organization and the individual to achieve performance improvement. Adam Smith states, "The capacities of individuals depended on their access to education". The same statement applies to organizations themselves, but it requires a much broader field to cover both areas. Human Resource Development is the integrated use of training, organization, and career development efforts to improve individual, group and organizational effectiveness. HRD develops the key competencies that enable individuals in organizations to perform current and future jobs through planned learning activities. Also, HRD ensures a match between individual and organizational needs 


\section{Performance management}

Performance management includes activities that ensure that goals are consistently being met in an effective and efficient manner. Performance management can focus on the performance of an organization, a department, employee, or even the processes to build a product or service. Armstrong and Baron defined it as a "strategic and integrated approach to increase the effectiveness of organizations by improving the performance of the people who work in them and by developing the capabilities of teams and individual contributors." It may be possible to get all employees to reconcile personal goals with organizational goals and increase productivity and profitability of an organization using this process. It can be applied by organizations or a single department or section inside an organization, as well as an individual person. Performance management is the systematic process by which an employer involves its employees, as individuals and members of a group, in improving organizational effectiveness in the accomplishment of employers mission and goals.

\section{Positive Organizational Behavior}

POB is defined as "the study and application of positively oriented human resource strengths and psychological capacities that can be measured, developed, and effectively managed for performance improvement in today's workplace". For a positive psychological capacity to qualify for inclusion in POB, it must be positive and must have extensive theory and research foundations and valid measures. In addition, it must be state like, which would make it open to development and manageable for performance improvement. Finally, positive states that meet the POB definitional criteria are primarily researched, measured, developed, and managed at the individual, micro level. The state-like criterion distinguishes POB from other positive approaches that focus on positive traits, whereas its emphasis on micro, individual-level constructs separates it from positive perspectives that address positive organizations and their related macro-level variables and measures. Meeting the inclusion criteria for POB are the state-like psychological resource capacities of selfefficacy, hope, optimism, and resiliency and, when combined, the underlying higher-order, core construct of Positive psychological capital or PsyCap.

\section{Resources}

[1] Organizational Behavior Management Network, Dr. John Austin, Dr. Dale Brethower, Dr. Alyce Dickinson. www.obmnetwork.com. 2009.

[2] Performance Management: Changing Behavior That Drives Organizational Effectiveness, 4th ed., Dr. Aubrey C. Daniels. Performance Management Publications, 1981, 1984, 1989, 2006. ISBN 0-937100-08-0

[3] Performance Management - Integrating Strategy Execution, Methodologies, Risk, and Analytics. Gary Cokins, John Wiley \& Sons, Inc. 2009. ISBN 978-0-470-44998-1

[4] Journal of Organizational Behavior Management, Routledge Taylor \& Francis Group. Published quarterly. 2009.

[5] Handbook of Organizational Performance, Thomas C. Mawhinney, William K. Redmon \& Carl Merle Johnson. Routledge. 2001.

[6] Bringing out the Best in People, Aubrey C. Daniels. McGraw-Hill; 2nd edition. 1999.

[7] Improving Performance: How to Manage the White Space in the Organization Chart, Geary A. Rummler \& Alan P. Brache. JosseyBass; 2nd edition. 1995.

[8] Human Competence: Engineering Worthy Performance, Thomas F. Gilbert. Pfeiffer. 1996.

[9] The Values-Based Safety Process: Improving Your Safety Culture with Behavior-Based Safety, Terry E. McSween. John Wiley \& Sons. 1995 .

[10] Performance-based Instruction: Linking Training to Business Results, Dale Brethower \& Karolyn Smalley. Pfeiffer; Har/Dis edition. 1998.

[11] Handbook of Applied Behavior Analysis, John Austin \& James E. Carr. Context Press. 2000

[12] Managing for Performance, Alasdair A. K. White Piatkus Books, 1995

[13] Luthans, F. (2002a). Positive organizational behavior: Developing and managing psychological strengths. Academy of Management Executive, 16(1): 57-72.

[14] Luthans, F. (2002b). The need for and meaning of positive organizational behavior. Journal of Organizational Behavior, 23: 695706.

[15] Luthans, F., \& Youssef, C. M. in 2007a. Emerging positive organizational behavior. Journal of Management, 33:321-349.

[16] Seligman, MD., \& Csikszentmihalyi, M. (2000). Positive psychology. American Psychologist, 55, 5-14.

[17] Blackwell Publishing Ltd 2005. Published by Blackwell Publishing, 9600 Garsington Road, Oxford, OX4 2DQ, 